\title{
THE EFFECT OF CRYPTORCHIDISM, CADMIUM AND ANTI-SPERMATOGENIC DRUGS ON FATTY ACID COMPOSITION OF RAT TESTIS
}

\author{
JAMES T. DAVIS AND JOHN G. CONIGLIO \\ Department of Biochemistry, Vanderbilt University School of Medicine, \\ $\mathcal{N}$ ashville, Tennessee \\ (Received 17th September 1966)
}

\begin{abstract}
Summary. Lipid and fatty acid composition of testes were determined in normal rats and in rats treated with various factors affecting spermatogenesis. Cryptorchidism and cadmium chloride treatment resulted in about $30 \%$ loss of weight of testes. In the former group there was a decrease in phospholipid and an increase in concentration of cholesterol and of triglycerides. In both groups there was a decrease in concentration of palmitate and docosapentaenoate compared to normal testes. Histological examination revealed atrophy of the germinal epithelium with disappearance of spermatids and spermatozoa and of most of the spermatocytes. Treatment of rats with two anti-spermatogenic drugs resulted in no change in the concentration of docosapentaenoic acid and a reduction in the number of spermatogonia and spermatocytes. The chemical and histological changes observed are consistent with the hypothesis that the docosapentaenoate of rat testicular tissue is associated with the spermatids and spermatozoa.
\end{abstract}

\section{INTRODUCTION}

An increase in the concentration of pentaenoic acid in testes of rats during the age period of 4 to 21 weeks was reported by Aaes-Jorgensen \& Holman (1958) and by Aaes-Jorgensen (1958) and during the period of 3 weeks to 3 months by Kirschman \& Coniglio (1961). In a more recent study Davis, Bridges \& Coniglio (1966) reported that the pentaenoic acid was $\Delta^{4,7,10,13,16}$ docosapentaenoic and that the three-fold increase in concentration reported previously (Kirschman \& Coniglio, 1961) actually occurred during the age period 4 to 9 weeks, a time period which coincided with appearance and maturation of spermatids. The docosapentaenoate, a member of the linoleate family, was shown to be derived by testicular synthesis from linoleate and arachidonate by Davis \& Coniglio (1966). Since the polyene is a major fatty acid of rat testicular tissue and of rat epididymal spermatozoa (Davis et al., 1966), a relationship was suggested between the increased amounts of the docosapentaenoate and the presence of spermatids and spermatozoa in testes of sexually mature rats. The present studies were designed to investigate 
further this relationship by determining the fatty acid composition of normal and degenerating testis. Degeneration was induced by cryptorchidism and by administration of cadmium chloride. In addition, the fatty acid composition of testis was also determined after administration of two anti-spermatogenic drugs, which caused specific changes in the germinal cells of the testis.

Animals

\section{MATERIALS AND METHODS}

Young, mature, male Sprague-Dawley rats were used. They were fed Purina laboratory chow throughout the study.

\section{Materials}

Diethyleneglycolsuccinate polyester for gas-liquid chromatography was a product of Applied Science Laboratories, State College, Pennsylvania. We are indebted to Lederle Laboratories, Pearl River, New York, and to SterlingWinthrop Research Institute, Rensselaer, New York, for generous gifts of triethylene melamine (2,4,6-tris-ethylenimino-s-triazine) and of Win 18441 $\left(\mathcal{N}, \mathcal{N}^{\prime}\right.$ bis(dichloroacetyl)-1,8-octamethylenediamine), respectively. Silica gel G for thin-layer chromatography was obtained from Research Specialties, Inc., Berkeley, California, U.S.A.

\section{Methods}

Cryptorchids. Two groups of young adult rats were made unilaterally cryptorchids by opening the lower abdomen and gently pulling one of the testes into the abdominal cavity. The inguinal canal was closed by one suture in order to hold the testis in the abdomen. The abdominal incision was closed with sutures and clamps after which each animal was given 150,000 units of penicillin G. The surgery was done under sterile conditions. A preliminary study of a group of five rats was followed by a more detailed study of twenty rats. The animals were allowed to live for 1 month, after which the testes were removed, frozen in acetone-dry ice mixture, and stored at $-20^{\circ} \mathrm{C}$ under nitrogen until analysed.

Experiments with cadmium chloride. Five rats (age 15 weeks) were injected in one testis with $200 \mu \mathrm{g} / \mathrm{kg}$ body weight of cadmium chloride which had been previously sterilized by heat. The control testis was injected with sterile saline solution. Total volume injected was $0 \cdot 15 \mathrm{ml}$. The animals were killed 28 days after injection, the testes removed, frozen and stored as described in the previous section.

Experiments with drugs. Four rats (age 22 weeks) were injected intraperitoneally with $0.2 \mathrm{mg} / \mathrm{kg}$ body weight of triethylene melamine daily for 5 days. Four rats of the same age injected with saline served as controls. All rats were killed 14 days later, the testes removed, frozen and stored as described previously.

Five rats (age 24 weeks) were injected subcutaneously with $70 \mathrm{mg} / \mathrm{kg}$ of Win 18441 (dispersed in water with approximately $50 \mathrm{mg}$ polyoxyethylene sorbitol mono-oleate) every other day for 21 days. Four rats injected with the same amount of dispersing agent served as controls. At 23 days the rats were killed, the testes removed, frozen and stored as before. 
Analyses. Analyses of lipids, gas-liquid and thin-layer chromatography, and fixation of histological sections were done using methods described previously (Davis et al., 1966).

\section{Cryptorchids}

\section{RESULTS}

In both groups of rats made unilaterally cryptorchids there was loss of weight of the testis maintained in the abdomen for 28 days to about one-quarter to one-third that of the control organ left in the scrotum. In the first group of five rats there was a loss of phospholipid along with loss of weight but no loss of cholesterol or triglyceride so that the relative concentrations of the latter two increased about two- to three-fold. A variable pattern of fatty acids was obtained. In one animal there was a significant decrease in the abdominal testis in $\mathrm{C}_{16: 0}, \mathrm{C}_{20: 4}$ and $\mathrm{C}_{22: 5}$ and an increase in $\mathrm{C}_{18: 0}$ and $\mathrm{C}_{18: 1}$. In other animals the cryptorchid testis contained less $\mathrm{C}_{16: 0}$, more $\mathrm{C}_{18: 0}$ and $\mathrm{C}_{18: 1}$, but changes in arachidonic and docosapentaenoic acids were not statistically significant.

More detailed analyses were done on the larger group of rats. Lipid composition of testes of these rats is shown in Table 1. The total amount and concentration of phospholipids were lower and the total amount and concentration of

TABLE 1

LIPID COMPOSITION OF NORMAL AND GRYPTORGHID TESTES*

\begin{tabular}{|c|c|c|c|c|}
\hline \multirow[b]{2}{*}{ Lipid fraction } & \multicolumn{2}{|c|}{ Total $\mu$ moles } & \multicolumn{2}{|c|}{ $\mu$ moles/g tissue } \\
\hline & $\begin{array}{c}\text { Normal } \\
\text { testis }\end{array}$ & $\begin{array}{c}\text { Cryptorchid } \\
\text { testis }\end{array}$ & $\begin{array}{c}\text { Normal } \\
\text { testis }\end{array}$ & $\begin{array}{c}\text { Cryptorchid } \\
\text { testis }\end{array}$ \\
\hline $\begin{array}{l}\text { Phospholipid } \\
\text { Cholesterol } \\
\text { Triglyceride } \\
\text { Cholesterol ester }\end{array}$ & $\begin{array}{r}28.6 \pm 2.9 \\
10.2 \pm 0.8 \\
5.0 \pm 0.3 \\
1.7 \pm 0.1\end{array}$ & $\begin{array}{l}7 \cdot 8 \pm 0.4 \\
7 \cdot 6 \pm 1 \cdot 3 \\
4 \cdot 7 \pm 0.2 \\
7.3 \pm 0.5\end{array}$ & $\begin{array}{c}17 \cdot 2 \pm 2 \cdot 2 \\
6 \cdot 0 \pm 0 \cdot 3 \\
2 \cdot 9 \pm 0.1 \\
1 \cdot 0 \pm 0.01\end{array}$ & $\begin{array}{r}12 \cdot 2 \pm 0.4 \\
12 \cdot 1 \pm 2 \cdot 1 \\
7 \cdot 4 \pm 0.5 \\
11.8 \pm 1.3\end{array}$ \\
\hline
\end{tabular}

* Results are mean values of nine animals \pm S.E.M.

cholesterol esters were higher in the cryptorchid than in normal testes. No significant loss of triglyceride and cholesterol occurred so that the concentrations ( $\mu$ moles/g tissue) of these fractions were higher in the cryptorchid testes than in the scrotal testes.

Results of gas chromatographic analyses done on total fatty acids from these organs are shown in Table 2. Differences between normal and cryptorchid testes are highly significant $(P<0.001)$ for $\mathrm{C}_{16: 0}$ and $\mathrm{C}_{22: 5}$ and significant $(P<0.02)$ for $\mathrm{C}_{20: 3}$ and $\mathrm{C}_{22: 4}$. The changes in concentrations of these fatty acids are reflected in the relative percentage composition also tabulated in Table 2.

Histological examination of the cryptorchid testes revealed that most tubules contained Sertoli cells and spermatogonia with very few primary spermatocytes (Pl. 1, Fig. 2; compare with Fig. 1). 
Rats treated with cadmium chloride

Treatment with cadmium chloride resulted in loss of weight of the testis to about one-half the weight of the non-injected organ of the same rat.

The relative percentage composition of the fatty acids is shown in Table 3 . In general, changes were similar (but of a smaller magnitude) to those seen in

TABLE 2

MAJOR FATTY ACID GOMPOSITION OF NORMAL AND GRYPTORGHID TESTES*

\begin{tabular}{|c|c|c|c|c|}
\hline \multirow{2}{*}{ Fatty acid } & \multicolumn{2}{|c|}{$m g / 100 \mathrm{~g}$ tissue } & \multicolumn{2}{|c|}{ Percent. of total fatty acids } \\
\hline & Normal & Cryptorchid & Normal & Cryptorchid \\
\hline $\begin{array}{l}\mathrm{C}_{16: 0} \\
\mathrm{C}_{18: 0} \\
\mathrm{C}_{18: 1} \\
\mathrm{C}_{18: 2} \\
\mathrm{C}_{20: 3} \\
\mathrm{C}_{20: 4} \\
\mathrm{C}_{22: 4} \\
\mathrm{C}_{22: 5}\end{array}$ & $\begin{array}{r}396 \pm 12 \\
63 \cdot 4 \pm 1 \cdot 4 \\
152 \pm 5 \cdot 9 \\
61 \cdot 6 \pm 3 \cdot 4 \\
10 \cdot 0 \pm 1 \cdot 1 \\
206 \pm 7 \cdot 5 \\
17 \cdot 8 \pm 2 \cdot 2 \\
208 \pm 7 \cdot 2\end{array}$ & $\begin{array}{c}215 \pm 13 \\
53 \cdot 1 \pm 8 \cdot 4 \\
141 \pm 9 \cdot 7 \\
63 \cdot 9 \pm 4 \cdot 3 \\
21 \cdot 9 \pm 2 \cdot 0 \\
184 \pm 10 \cdot 0 \\
26 \cdot 6 \pm 2 \cdot 3 \\
66 \cdot 4 \pm 6 \cdot 6\end{array}$ & $\begin{array}{r}35.6 \pm 1 \cdot 1 \\
5.7 \pm 0.1 \\
13.7 \pm 0.5 \\
5.5 \pm 0.3 \\
0.9 \pm 0.1 \\
18.4 \pm 0.7 \\
1.6 \pm 0.2 \\
18.7 \pm 0.6\end{array}$ & $\begin{array}{r}27.8 \pm 1.7 \\
6.9 \pm 0.7 \\
18.2 \pm 1.3 \\
8.3 \pm 0.6 \\
2.8 \pm 0.3 \\
23.8 \pm 1.4 \\
3.4 \pm 0.3 \\
8.6 \pm 0.8\end{array}$ \\
\hline
\end{tabular}

* Results are given as mean values of fifteen animals \pm S.E.M.

TABLE 3

MAJOR FATTY ACID COMPOSITION OF NORMAL AND GADMIUM-TREATED RATS*

\begin{tabular}{l|r|r}
\hline \multirow{2}{*}{ Fatty acid } & \multicolumn{2}{|c}{ Percent. of total fatty acids } \\
\cline { 2 - 3 } & \multicolumn{1}{|c}{ Normal } & Cadmium-treated \\
\hline $\mathrm{C}_{16}: 0$ & $35 \cdot 7 \pm 0 \cdot 1$ & $31 \cdot 3 \pm 1 \cdot 1$ \\
$\mathrm{C}_{18}: 0$ & $5 \cdot 8 \pm 0 \cdot 4$ & $10 \cdot 1 \pm 0 \cdot 5$ \\
$\mathrm{C}_{18}: 1$ & $12 \cdot 5 \pm 0 \cdot 4$ & $11 \cdot 8 \pm 0 \cdot 3$ \\
$\mathrm{C}_{18}: 2$ & $4 \cdot 9 \pm 0 \cdot 3$ & $8 \cdot 8 \pm 1 \cdot 5$ \\
$\mathrm{C}_{20}: 3$ & $1 \cdot 1 \pm 0 \cdot 1$ & $1 \cdot 6 \pm 0 \cdot 1$ \\
$\mathrm{C}_{20}: 4$ & $17 \cdot 7 \pm 1 \cdot 1$ & $20 \cdot 1 \pm 0 \cdot 2$ \\
$\mathrm{C}_{22}: 4$ & $1 \cdot 9 \pm 0 \cdot 4$ & $3 \cdot 7 \pm 0 \cdot 3$ \\
$\mathrm{C}_{22}: 5$ & $18 \cdot 2 \pm 0 \cdot 3$ & $10 \cdot 3 \pm 0 \cdot 6$ \\
\hline
\end{tabular}

* Results are given as mean values of five animals \pm S.E.M.

the experiments with cryptorchids. Significant decreases in the cadmium-treated testes were observed in the relative concentrations of palmitate $(P<0.02)$ and docosapentaenoate $(P<0.001)$ and increases in stearate $(P<0.003)$, oleate $(P<0.007)$ and docosatetraenoate $(P<0.020)$. An increase in concentration of eicosatetraenoate was of borderline significance $(P<0.074)$.

\section{EXPLANATION OF PLATE 1}

Testes from normal and treated rats $\times 72$.

Fig. 1. Normal testis.

FIG. 2. Cryptorchid testis (arrows point to spermatocytes).

FIG. 3. Cadmium chloride-injected testis.

Fig. 4. Testis of rat injected with triethylenemelamine. 


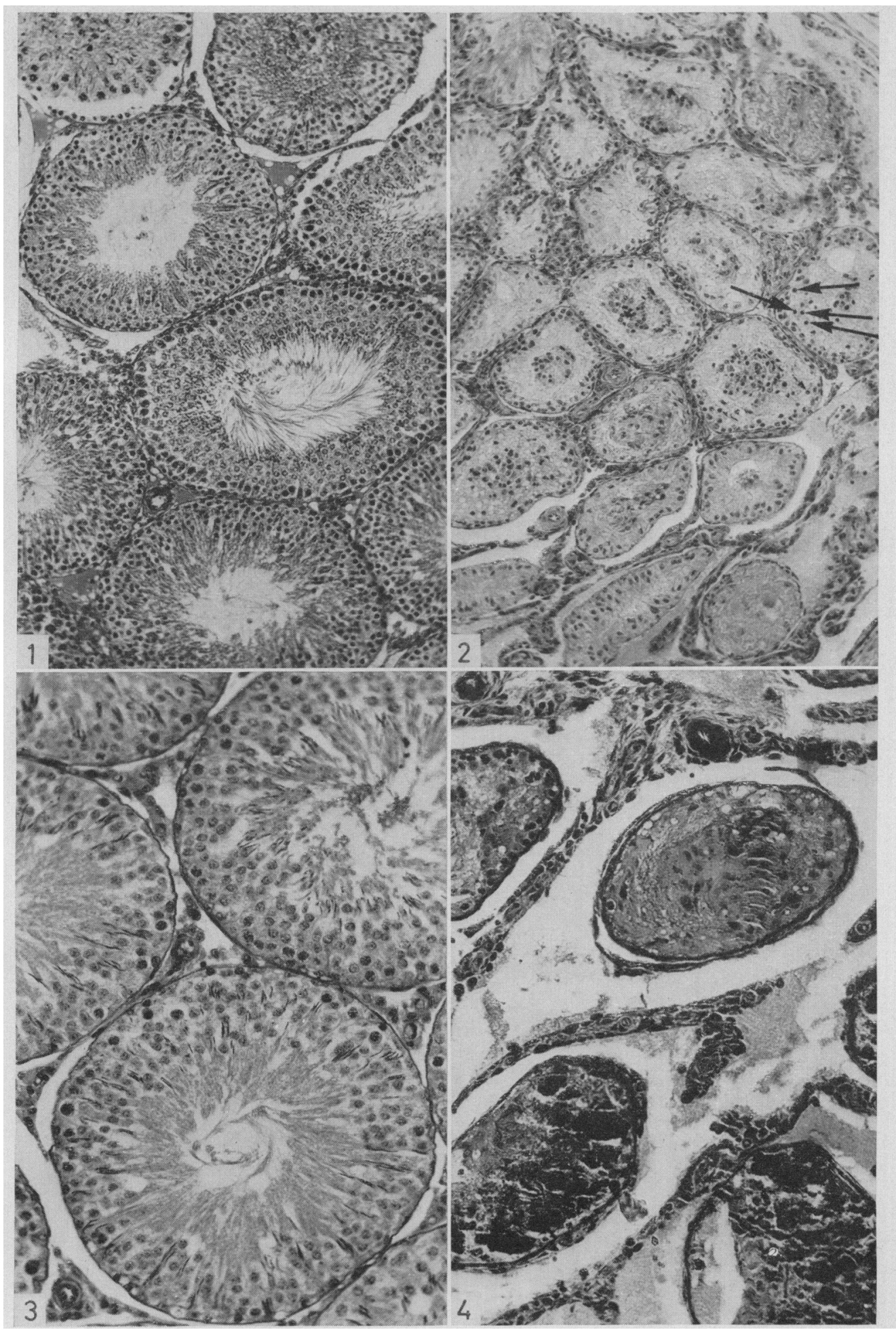

(Facing t. 410) 
Histological examination of the cadmium-treated testes revealed severe atrophy of the germinal epithelium. Only a few tubules contained young primary spermatocytes. Approximately $30 \%$ of the tubules examined were devoid of any germinal cells while only a few of these tubules still contained Sertoli cells (Pl. 1, Fig. 3). The untreated testes were normal histologically.

\section{Rats treated with triethylene melamine}

Testes of rats treated with triethylene melamine weighed about $15 \%$ less than those of control rats.

Results of analyses of the fatty acid composition by gas-liquid chromatography are shown in Table 4 . There were no significant differences in testicular fatty acid composition between the two groups of rats.

Histological examination of the testes of rats treated with triethylene melamine indicated a decrease in the number of spermatogonia and primary spermatocytes. All other cellular components appeared normal (Pl. 1, Fig. 4).

TABLE 4

MAJOR FATTY AGID COMPOSITION OF TESTES OF NORMAL RATS AND OF RATS TREATED WITH TRIETHYLENEMELAMINE*

\begin{tabular}{l|r|r}
\hline \multirow{2}{*}{ Fatty acid } & \multicolumn{2}{|c}{ Percent. of total fatty acids } \\
\cline { 2 - 3 } & \multicolumn{1}{|c}{ Normal } & Triethylenemelamine-treated \\
\hline $\mathrm{C}_{16: 0}$ & $32 \cdot 3 \pm 1 \cdot 1$ & $36 \cdot 6 \pm 2 \cdot 0$ \\
$\mathrm{C}_{18: 0}$ & $4 \cdot 7 \pm 0.2$ & $4 \cdot 7 \pm 0 \cdot 3$ \\
$\mathrm{C}_{18: 1}$ & $12 \cdot 7 \pm 0 \cdot 3$ & $12 \cdot 7 \pm 0 \cdot 6$ \\
$\mathrm{C}_{18: 2}$ & $5 \cdot 2 \pm 0 \cdot 2$ & $5 \cdot 1 \pm 0 \cdot 1$ \\
$\mathrm{C}_{20}: 3$ & $2 \cdot 1 \pm 0 \cdot 1$ & $1 \cdot 0 \pm 0 \cdot 1$ \\
$\mathrm{C}_{20: 4}$ & $17.4 \pm 0 \cdot 1$ & $16.9 \pm 1 \cdot 1$ \\
$\mathrm{C}_{22: 4}$ & $1.4 \pm 0 \cdot 4$ & $1 \cdot 6 \pm 0 \cdot 5$ \\
$\mathrm{C}_{22: 5}$ & $20.9 \pm 0.4$ & $18 \cdot 7 \pm 1 \cdot 4$ \\
\hline
\end{tabular}

* Results are given as mean values of four animals \pm s.E.M.

\section{Rats treated with $\mathrm{N}, \mathrm{N}^{\prime}$ bis (dichloroacetyl)-1,8-octamethylenediamine}

Rats treated with this drug had testes which weighed approximately $20 \%$ less than organs of normal controls. Results of gas-liquid chromatographic analyses showed that only the relative concentrations of palmitic and docosatetraenoic acids changed in a manner similar to the experiments with cadmium and cryptorchids. Concentrations of other fatty acids, including docosapentaenoic, remained constant.

A reduction in the number of primary spermatocytes in most tubules of testes of treated rats was observed on histological examination. All other cellular components appeared normal.

\section{DISCUSSION}

The morphological changes seen in testes of cryptorchids were consistent with those reported by others (Nelson, 1951). According to Clegg (1963) in cryptorchid testes examined 28 days after operation no spermatids were present and 
there was a reduced number of spermatogonia, early primary spermatocytes and late primary spermatocytes compared to controls. Degenerative changes were maximal about the 15th day after operation followed by a period of partial regeneration. In our experiment few spermatocytes were seen in the tubules 28 days after the operation.

The three- to four-fold decrease seen in the phospholipid content of testes of cryptorchids may be explained by loss of membrane structures which are rich in phospholipids. The loss of phospholipid paralleled the weight loss of these organs.

Our results of analyses of cholesterol confirm those of Perlman (1950) who reported an increase in cholesterol and cholesterol esters in testes of cryptorchid rats. Rats injected with testosterone to maintain spermatogenesis showed no changes in concentrations of these lipid fractions in testes. Perlman also demonstrated by histological techniques that most of the cholesterol was associated with the germinal epithelium. In our studies, there was no increase in the total amount of cholesterol although the concentration increased. It is possible that as the germinal epithelium atrophied the cholesterol simply accumulated in the testis.

A consistent and significant decrease in the concentration of palmitic and docosapentaenoic acids was seen in testes of cryptorchids and in cadmiumtreated testes. Atrophy of the germinal epithelium was more severe in the latter than in the former. That cadmium administration produces profound damage to the testis was first demonstrated by Parizek \& Zahor (1956). Recent investigations (Gunn, Gould \& Anderson, 1963; Chiquoine, 1964; Mason, Brown, Young \& Nesbit, 1964) indicate that the primary site of action of cadmium is the vascular supply to the tubules with subsequent secondary damage to the germinal epithelium.

A third method used to cause injury to testicular tissue was the use of antispermatogenic drugs. It was demonstrated by Bock \& Jackson (1957) that triethylenemelamine causes temporary sterility in the male rat. Use of certain members of a series of bis-(dichloroacetyl)diamines to curtail spermatogenesis was reported by Coulston, Beyler \& Drobeck (1960). A quantitative analysis by Steinberger (1962) of the testicular germinal epithelium of rats treated with triethylenemelamine at the same dose level as used in this study showed that 14 days after treatment there was a drastic reduction in the number of type $\mathbf{B}$ spermatogonia and primary spermatocytes.

In the present study, loss of spermatids in cryptorchid and cadmium-treated testes was accompanied by a decrease in concentration of docosapentaenoic acid. No such decrease of docosapentaenoate occurred in the testes of rats treated with the drugs, in which case the spermatids remained normal. Spermatocytes were decreased in number, more so in cryptorchid testes than in testes of rats treated with triethylene melamine. However, the major difference was the presence or absence of spermatids, and it may be postulated that docosapentaenoic acid in rat testicular tissue is predominantly associated with spermatids and spermatozoa. These findings agree with our previous observation that rat epididymal spermatozoa contain docosapentaenoate as a major fatty acid (Davis et al., 1966). 
ACKNOWLEDGMENTS

This work was supported by Grant No. AM 06483 from the United States Public Health Service. The work described here has been included in a thesis submitted in partial requirement for the Ph.D. degree, Vanderbilt University, by J. T. Davis, who was a predoctoral trainee of the National Institutes of Health (Training Grant No. 2 TI GM-300) during this time. We thank Dr G. H. Barney, Department of Pathology, for kind assistance with the histological preparations and Dr Marie Claire Orgebin-Crist, Department of Obstetrics and Gynecology, for much valuable advice.

\section{REFERENCES}

Aaes-Jorgensen, E. (1958) Essential fatty acid deficiency. III. Effects of conjugated isomers on dienoic and trienoic fatty acids in rats. 7 . Nutr. 66, 465.

Aaes-Jorgensen, E. \& Holman, R. T. (1958) Essential fatty acid deficiency. I. Content of polyenoic acids in testes and heart as an indicator of EFA status. $\mathcal{F}$. Nutr. 65, 633 .

Bock, M. \& JAckson, H. (1957) The action of triethylenemelamine on the fertility of male rats. Br. $\mathcal{J}$. Pharmac. Chemother. 12, 1 .

Chiquorne, A. (1964) Observations on the early events of cadmium necrosis of the testis. Anat. Rec. $149,23$.

Clegg, E. J. (1963) Studies on artificial cryptorchidism: generative and regenerative changes in the germinal epithelium of the rat testis. $\mathcal{F}$. Endocr. 27, 241.

Coulston, F., Beyler, A. L. \& Drobeck, H. P. (1960) The biologic actions of a new series of bis(dichloroacetyl)diamines. Toxic. appl. Pharmac. 2, 715.

Davis, J. T., Bridges, R. B. \& Coniglio, J. G. (1966) Changes in lipid composition of the maturing rat testis. Biochem. 7. 98, 342.

Davis, J. T. \& Coniglio, J. G. (1966) The biosynthesis of docosapentaenoic and other fatty acids by rat testes. F. biol. Chem. 241, 610 .

Gunn, S. A., Gould, T. C. \& Anderson, W. A. D. (1963) The selective injurious response of testicular and epididymal blood vessels to cadmium and its prevention by zinc. Am. F. Path. 42, 685 .

Kirschman, J. C. \& Coniglio, J. G. (1961) Polyunsaturated fatty acids in tissues of growing male and female rats. Archs Biochem. Biophys. 93, 297.

Mason, K. E., Brown, J. A., Young, J. O. \& Nesbit, R. R. (1964) Cadmium-induced injury of the rat testis. Anat. Rec. 149, 135.

NeLson, W. O. (1951) Mammalian spermatogenesis: effect of experimental cryptorchidism in the rat and non-descent of the testis in man. Recent Progr. Horm. Res. 6, 29.

Parizek, J. \& Zahor, A. (1956) Effect of cadmium salts on testicular tissue. Nature, Lond. 177, 1036.

Perlman, P. L. (1950) The functional significance of testis cholesterol in the rat: effects of hypophysectomy and cryptorchidism. Endocrinology, 46, 341.

SteinBerger, E. (1962) A quantitative study of the effect of an alkylating agent (triethylenemelamine) on the seminiferous epithelium of rats. J. Reprod. Fert. 3, 250. 